\title{
BUDISMO UNIVERSAL, BUDISMO INDIVIDUAL. ANÁLISIS DEL INTERÉS POR LA ESPIRITUALIDAD ORIENTAL EN OCCIDENTE
}

\author{
UNIVERSAL BUDDHISM, INDIVIDUAL BUDDHISM: \\ ANALYSIS OF THE INCREASING WESTERN \\ INTEREST IN EASTERN SPIRITUALITY
}

\section{BUDISMO UNIVERSAL, BUDISMO INDIVIDUAL: ANÁLISE DO CRESCENTE INTERESSE OCIDENTAL PELA ESPIRITUALIDADE ORIENTAL}

Jean Paul Sarrazín*

\section{RESUMEN}

Este artículo analiza el creciente interés generado por el budismo en Occidente; tomando como referencia diferentes investigaciones históricas y sociológicas, se procede a una revisión crítica de este fenómeno a la luz de algunas teorías sobre la modernidad. En un primer momento se considera la evolución de las representaciones occidentales sobre el budismo y sobre el Tíbet, lugar cuya cultura se asume como puramente budista. En un segundo momento se demuestran las relaciones existentes entre este fenómeno y las nuevas formas del creer, dominantes en un sector de la población occidental; se subraya, además, la importancia de inscribir el fenómeno budista dentro del pluralismo

* Doctor en Sociología, Université de Poitiers, Poitiers, Francia, (2010). Docente-Investigador de la Universidad de Antioquia, Colombia. Miembro del Grupo de Investigación Religión, Cultura y Sociedad. Este artículo procede de investigaciones realizadas por el autor de manera independiente y por fuera de un proyecto avalado institucionalmente.

Correo electrónico: jpsarra@yahoo.com

orcid.org/0000-0002-8022-4674

Artículo recibido el 16 de noviembre de 2015 y aprobado para su publicación el 24 de agosto de 2016. 
contemporáneo que valora una cierta Otredad. Se concluye, entonces, que el auge del budismo -aunque aparentemente la expresión dé un giro en contrasentido a la modernidad -, se comprende en el marco de ciertos procesos muy modernos, como la desinstitucionalización de la religión, la individualización y la crítica cultural frente a una supuesta crisis de sentido en occidente.

PALABRAS CLAVE

Budismo, Representaciones, Desinstitucionalización de la Religión, Modernidad, Alteridad.

\begin{abstract}
The article analyses the increasing interest in Buddhism among Western Culture. Based on different historical and sociological researches, a critical review of this phenomenon is undertaken in the light of theories concerning Modernity. First, it considers the evolution of western representations of Buddhism and Tibet -bearing in mind that the culture of the latter has been generally seen as purely Buddhist. Second, it shows the existent relation between the studied phenomenon and the new forms of believing which are dominant in a significant sector of Western society. Then, it highlights the relevance of considering the phenomenon of Buddhism within the contemporary pluralism that values a certain idea of Otherness. Therefore, it is concluded that the rise of Buddhism, though apparently might be the expression of a turn in the opposite direction of Modernity, might be understood within the background of quite modern processes such as deinstitutionalization of religion, individualization and the cultural critique that is resultant of the so-called crisis of meaning in the West.
\end{abstract}

\title{
KEY WORDS
}

Buddhism, Representations, Deinstitutionalization of Religion, Modernity, Alterity.

\section{RESUMO}

Este artigo analisa o crescente interesse gerado pelo budismo no Ocidente. Tomando como referência diferentes pesquisas históricas e sociológicas, propõe-se uma revisão crítica desse fenômeno à luz de algumas teorias sobre a modernidade. Em um primeiro momento, considera-se a evolução das representações ocidentais sobre o budismo e sobre o Tibete, local cuja cultura se assume como puramente budista. Em um segundo momento, demostram-se as relações existentes entre esse fenômeno e as novas formas de crer, dominantes em um setor da população ocidental. Destacase, além disso, a importância de inscrever o fenômeno budista dentro do pluralismo contemporâneo, que valoriza certa Alteridade. Conclui-se, então, que o auge do budismo - mesmo que, aparentemente, a expressão dê um giro em contrassenso à modernidade - compreende-se no âmbito de certos processos muito modernos, como a desinstitucionalização da religião, a individualização e a crítica cultural diante de uma suposta crise do sentido no Ocidente.

\section{PALAVRAS-CHAVE}

Budismo, Representações, Desinstitucionalização da Religião, Modernidade, Alteridade 


\section{Introducción}

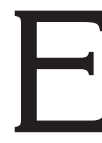

I interés por las religiones orientales es una tendencia difundida en muchos países occidentales u occidentalizados como Francia, Alemania, Reino Unido, Estados Unidos, Australia, Chile, Argentina, Brasil, etc. (Lenoir, Las Metamorfosis). Dentro de esta tendencia globalizada, se destaca la expansión del budismo en Occidente ${ }^{1}$ (Liogier, Le Bouddhisme), especialmente en las clases media y alta de las ciudades, sectores poblacionales a los que nos referiremos en este artículo. Solo en Francia, en 1999, se estimaban aproximadamente cinco millones de franceses interesados en el budismo, lo cual hace parte de una tendencia en aumento (Lenoir, Las Metamorfosis 32). ¿Cómo explicar tal fenómeno masivo en sociedades con una exigua inmigración de budistas provenientes de Asia, y en una modernidad supuestamente secularizada?

Es importante señalar de antemano que en países occidentales existe una considerable mediatización de los eventos relacionados con el budismo, en particular con su vertiente tibetana. Si bien es cierto que una ínfima proporción de los adeptos al budismo tiene contacto social con los budistas asiáticos, es notable el consumo de elementos culturales identificados como budistas por parte de algunos sectores de las sociedades occidentales a los que nos referiremos.

Este artículo muestra una reflexión realizada a partir de investigaciones empíricas sobre el fenómeno de interés por el budismo en Occidente (Lenoir, Le Bouddhisme; Sarrazin, Branchés), las cuales ponen de manifiesto la amplia difusión de representaciones positivas acerca de esta religión oriental. En efecto, las investigaciones históricas y sociológicas a propósito de este fenómeno son aquí revisitadas a la luz de teorías sobre la modernidad tardía y sus nuevas formas del creer, utilizando especialmente conceptos analíticos como la desinstitucionalización y la individualización.

1 Cuando utilizamos el término "Occidente" como categoría analítica, nos referimos simplemente a países que hacen parte de los continentes europeo y americano. Sin embargo, también se utilizará el término tal como aparece en los discursos analizados. La diferencia entre uno y otro se comprenderá en función del contexto lingüístico de utilización. 
Las representaciones que circulan en Occidente a propósito del budismo ${ }^{2}$ no serán consideradas como "deformaciones" de un supuesto budismo original y auténtico; sino como un factor determinante a la hora de explicar el interés por esta denominación religiosa en el mundo, como se indica en: 'No hay realmente un 'verdadero' budismo, solamente hay budismos promulgados por diferentes grupos humanos" (Obadia 35). Sin tomar una posición purista o moralizante respecto al tema, el objetivo es comprender los esquemas a través de los cuales el budismo es representado positivamente en Occidente, teniendo en cuenta los factores socioculturales que permiten que esas representaciones surjan y se reproduzcan.

De esta manera, en la primera parte del artículo veremos ejemplos de la evolución histórica de aquellas representaciones. En dicho recorrido se observa que ya a finales del siglo XVIII existen indicios de una tendencia a idealizar o representar positivamente lo oriental, tendencia que acá llamaremos orientalismo, la cual no hará sino reforzarse más tarde y expresarse a través de descripciones noveladas y ensayos filosóficos, entre otros. En una segunda parte del artículo, se analizan más específicamente las nuevas formas del creer, un fenómeno propio de la modernidad tardía en el cual se enmarca la adopción del budismo como una espiritualidad benéfica para el individuo occidental.

Dado que el budismo claramente es considerado como una religión extranjera (Hourmant 28), una última parte del artículo es dedicada al estudio de este fenómeno en tanto que expresión de una cierta valoración de alteridad cultural, valoración que se realiza a través de la espiritualización de sus contenidos, y que es especialmente frecuente entre los sectores poblacionales con capital cultural elevado. Esta espiritualización de las "otras culturas" o de las "religiones no occidentales", como veremos, juega un papel determinante en la construcción de una imagen positiva del Tíbet y del budismo en general. Así, de manera más amplia, esta reflexión se plantea como un aporte a la comprensión de la valoración positiva

2 Entendemos por representación: "[...] el conjunto de informaciones, creencias, opiniones y actitudes a propósito de un objeto dado” (Abric 59). 
de esas "otras religiones", que se relaciona a su vez con la búsqueda de alternativas espirituales y cambios culturales respecto a una supuesta crisis de sentido en Occidente.

\section{Evolución de las representaciones en la historia}

Desde los primeros misioneros católicos y exploradores venecianos -dos siglos antes de que Colón llegara a América-, los europeos han proyectado sus imaginarios sobre los asiáticos. Las prácticas religiosas de ese territorio constituyeron en el pasado el argumento para considerar a los tibetanos como pueblos atrasados cuyas formas de vida fueron incluso equiparadas al oscurantismo de la Edad Media. Los misioneros franceses que estuvieron en el Tíbet trataron a los lamas tibetanos como "hipócritas, egoístas, falsos doctores y servidores de Satán", y clasificaron sus doctrinas como idolatría y superstición (Li 219). Más tarde, en la época victoriana, "[...] el budismo del Tíbet no fue reconocido como un verdadero budismo [...y además] se consideraba que la sociedad tibetana estaba corrupta y estancada" (López 203).

En contraste con todo lo anterior, otra vertiente de discursos e imaginarios, cada vez más comunes en tiempos recientes, muestra al budismo como una religión interesante y al budismo tibetano como su versión más auténtica, ya que el lejano y montañoso Tíbet, poco visitado por los colonizadores europeos, sería el lugar donde mejor se habría preservado la espiritualidad búdica original. Las representaciones del Tíbet como un pueblo tradicional, pacífico y espiritual, hoy comunes (Sarrazin, Branchés), constituyen un fenómeno que no encontramos antes del siglo XIX.

Pero para comprender mejor la valoración contemporánea del budismo es necesario considerar un proceso mucho más amplio, a saber, la valoración positiva de lo Oriental en general. En efecto, existen ancestros de este orientalismo a finales del siglo XVIII, particularmente entre artistas, literatos y filósofos. Diderot y Rousseau, por citar autores muy conocidos, elogiaron un imaginado de Oriente y, como Montaigne antes que ellos, indicaron el posible valor que tenían las culturas no europeas para los 
mismos europeos. No obstante, la mayor parte de estos intelectuales admiradores de la alteridad cultural nunca estuvo fuera de Europa o ciertamente no convivió en las sociedades que imaginaban llenas de virtudes. Se trata de "un elogio en el desconocimiento" (Todorov 306) que debemos analizar críticamente.

El Orientalismo del siglo XIX profundizó la idealización y multiplicó las obras de ese corte difundiéndolo en una población un poco más amplia, aunque todavía extremadamente minoritaria si se compara con lo sucedido en los siglos XX y XXI y que veremos más adelante. Como Todorov atesta a lo largo de su obra, son muchos los autores, especialmente románticos, los que contribuyeron a la difusión de este orientalismo: Chateaubriand, Nerval, Lahontan, etc. Es posible notar la presencia del orientalismo también en obras de autores influyentes del siglo XIX y la primera mitad del XX: Goethe, Borges, Emerson, Hesse, Tolstoi. Las espiritualidades orientales interesaron también a filósofos como Nietzsche, Schopenhauer, Bergson o Heidegger e influyeron decididamente en psicólogos de renombre como Karl Jung (Lenoir, "Les Spiritualités" 2403). Todo esto contribuyó a que el budismo se difundiera a través de los libros, se "intelectualizara", se empezara a ver como un aporte a la filosofía o a la psicología o se incorporara a un saber intelectual desligado de normatividades y prácticas propias de la institucionalidad religiosa asiática.

A finales del siglo XIX surge un movimiento que contribuyó considerablemente a sustentar el interés por el budismo en Occidente. Se trata de la Sociedad Teosófica, cuyos objetivos eran "promover el estudio de las literaturas, religiones, filosofías y ciencias del Oriente, y mostrar la importancia de éstas para la humanidad" (Lenoir, "Les Spiritualités" 2404). La Sociedad Teosófica pretendía encontrar "una convergencia universal de las religiones" (Lenoir, "Les Spiritualités" 2404). En La Doctrina Secreta, libro escrito por Madame Blavatsky, cofundadora de la Sociedad, se define la teosofía como "la esencia de todas las religiones", y para hallarla, se promueve el estudio de lugares lejanos como el Tíbet, Japón, China, India o Egipto (Hammer 116). Se trataba de un proyecto que rescataría todas aquellas sabidurías ocultas o relegadas por la modernidad occidental racionalista. 
La espiritualidad se encontraría en todas esas otras tradiciones perdidas o rechazadas, pero sería necesario ir a sus fuentes, para así encontrar su forma más pura (López 97), su esencia. Por supuesto, dicha esencia dependería del criterio de quien la busque, y quienes se asignan la capacidad de identificar y rescatar la versión pura, auténtica y valiosa de esas otras religiones, son los intelectuales occidentales de la modernidad. Por demás, como señala Hannegraaf, las ideas de intelectuales como los de la Sociedad Teosófica son en realidad una recuperación de la moral cristiana y el esoterismo europeo, pero dichas con términos exóticos provenientes principalmente de religiones orientales.

Otra fuente importante de imaginarios sobre el Oriente, y particularmente sobre el Tíbet, es la obra de Alexandra David-Neel, exploradora francesa y también conocedora de la Sociedad Teosófica, quien fue bien conocida especialmente en Europa por sus libros sobre un supuesto Tíbet auténtico y mágico. En 1929, por ejemplo, David-Neel publica Místicos y Magos del Tíbet -libro vendido aun hoy en las librerías de Hispanoamérica bajo ese título-. Esta publicación llena de exotismo y aventura, narra las experiencias de una exploradora europea que vivió catorce años en el Tíbet en una época en que la entrada a los extranjeros estaba prohibida. Gracias a este supuesto acceso excepcional a una cultura desconocida, se nos revelan conocimientos "secretos" sobre una sociedad donde se practicaría la telepatía, los desdoblamientos, los viajes astrales y donde los monjes pasarían meses en las altas montañas sin alimento.

Pero quizás el "texto tibetano" más leído en Occidente, al menos durante el siglo XX, es El Libro Tibetano de los Muertos, escrito por el estadounidense Walter Evans-Wentz en 1927, quien también estaba influenciado por los discursos de la Sociedad Teosófica. Según su autor, se trata de la "transcripción" de las palabras de un sabio tibetano, acompañado y comentado por introducciones, prefacios y posfacios redactados por Evans-Wentz y otros comentaristas occidentales, lo cual constituye aproximadamente la mitad del contenido del libro. Allí, el autor presupone una marcada dicotomía entre un Oriente místico y un Occidente materialista, este último necesitado del primero para redimir sus errores. El Tibet es presentado allí de manera acrítica, como el depositario 
de una sabiduría milenaria que trasciende los tiempos. Todo ello va a acompañado de una serie de detalles supuestamente etnográficos, que nunca han sido corroborados, narrados mediante un lenguaje romántico y lleno de exotismos.

En una vena similar, esta la también muy conocida obra de Lobsang Rampa. Aunque este nombre parezca ser tibetano, se trataba en realidad de un inglés experto en el género literario de ficción (Lenoir, "Les Spiritualités"; López). El éxito de sus libros fue inmenso, incluso en América Latina; de hecho, es el autor del mayor número de libros a propósito del Tíbet y del budismo, contribuyendo así a construir desde el año 1950 un imaginario de corte místico-esotérico sobre ello. Allí se mezcla el budismo con temas como el aura, los extraterrestres, los tiempos prehistóricos o las etapas de la evolución espiritual de la humanidad. Uno de los volúmenes sobresalientes, en términos de ventas, es "El Tercer Ojo", clasificado en algunas librerías bajo la rúbrica de "aventura misteriosa" y al lado de libros sobre la Nueva Era, la alquimia o la astrología. Desde la primera página de este libro, el autor asegura ser tibetano, nos anticipa que describirá el país "más misterioso del mundo", y se describe como un ser privilegiado gracias a quien se preservará una sabiduría ancestral y preciosa (algo similar a como se representaba David-Neel). Acusa al "Occidente" de ser excesivamente "escéptico y materialista" (151) y añade que el mundo occidental "es demasiado precipitado para ocuparse de las cuestiones del espíritu”. Según López, para muchos jóvenes intelectuales y académicos en Occidente, las "fascinantes descripciones" de este libro los motivaron a interesarse por un estudio más profundo sobre el budismo.

Este tipo de reinterpretaciones místico-esotéricas del budismo siempre pueden evadir la confrontación con una versión popular o "vulgar" de la religión tal como es practicada en las comunidades. Se asume comúnmente que si la versión "espiritual" y "pura" -siempre más interesante para el intelectual occidental- no coincide con lo que se observa entre el pueblo practicante, es porque este último desconoce o malinterpreta las verdaderas enseñanzas espirituales de los maestros ancestrales. Esa referencia a una espiritualidad auténtica más allá de lo que las comunidades realmente creen y hacen, paradójicamente permite 
que se construya un budismo basado en reinterpretaciones totalmente moderno-occidentales.

Un segundo Libro de los Muertos, que también fue un best-seller, aparece en 1992, igualmente en inglés, pero esta vez escrito por el nativo Sogyal Rimpoché, nacido en el Lejano Oriente. El que ciertos individuos de origen asiático prediquen las versiones espirituales a las que nos hemos referimos anteriormente, podría constituir una prueba de que dichas versiones sí corresponden a una espiritualidad asiática auténtica y milenaria. No obstante, siempre es necesario revisar la historia de vida de esas personas para notar que difícilmente se les puede considerar como representantes de una cultura lejana y tradicional. Sogyal Rimpoché, por ejemplo, pertenece a las élites occidentalizadas de su sociedad, estudió en la Universidad de Cambridge y estaba conectado con la cultura globalizada décadas antes de hacerse famoso. No es de extrañar que allí se plantee una aproximación al budismo similar a la de Evans-Wentz, pero en un lenguaje aún más contemporáneo.

Según López, "[...] la inmensa popularidad de Evans-Wentz y Sogyal se basa en la homogenización del texto tibetano como si fuese una sabiduría atemporal y universal" (97). En efecto, siguiendo en parte el precepto de la Sociedad Teosófica, Sogyal dice que para los tibetanos, Gandhi, Shakespeare, Einstein, la Madre Teresa de Calcuta o incluso Miguel Ángel serían bodhisattvas ${ }^{3}$; y en la misma línea, compara al Dalai-Lama con San Francisco de Asís. Tanto para Evans-Wentz como para Sogyal se trata de develar el "verdadero sentido" de las creencias del budismo tibetano, un sentido que corresponde con las nociones de espiritualidad presentes en Occidente, pero referenciando un supuesto origen cultural lejano.

El proceso de construcción de "comunidades imaginadas" en la modernidad, como ha señalado Anderson, es facilitado por la imprenta. Y en efecto, los textos impresos han contribuido a construir un Oriente imaginado, prescindiendo del contacto real con ese lugar, sus gentes, sus prácticas y

3 Personas iluminadas que permanecen en la Tierra para ayudar a los demás a alcanzar la Iluminación. 
su religiosidad vivida, generando que un gran tapiz de información sobre el budismo cubra a los budistas asiáticos. Sin embargo, cabe recordar que una religión no se puede reducir a un conjunto de discursos intelectuales. Una religión solo existe en las comunidades que la viven, articulándose a una cosmovisión, a un nomos y a una forma de vida (Berger).

De otra parte, por más de que este orientalismo parezca hacerle un favor al Oriente asignándole cualidades valoradas positivamente, se trata, como dice Said, de una "formidable estructura de dominación cultural". Desde allí, se construye una alteridad que no se pone en duda. Este discurso sobre el otro se presenta tan autoevidente que ha hecho olvidar las innumerables dificultades de traducción y los complejos dispositivos interpretativos que han sido necesarios para llegar a traspasar los conceptos de una religión tradicional asiática a una tradición lingüística y cultural moderno-occidental ${ }^{4}$.

En el proceso de construcción de las representaciones sobre el budismo no se puede negar el papel del Dalai-Lama, varios Rimpochés y un cierto número de tibetanos que emigraron en su mayoría a Europa y Norteamérica, huyendo principalmente de la colonización china. El DalaiLama, líder político del Tíbet y figura más mediatizada del budismo, claramente ha sabido reproducir aquella idea de un pueblo tradicional y profundamente espiritual, pero amenazado por el totalitarismo comunista, aliando así espiritualidad y política, y ganando adeptos occidentales a su proyecto por un Tíbet autónomo ${ }^{5}$. El conflicto mismo con la China ha venido a representar la lucha entre el mal de un régimen materialista contra la bondad de una minoría espiritual.

No obstante, hay que notar que la labor de estos tibetanos y su prédica del budismo se llevan a cabo a través de lenguas europeas -principalmente el inglés- y apelando a esquemas conceptuales muy modernos. También hay que decir que muchos de ellos vieron la utilidad económica, política y social de presentarse como un pueblo netamente religioso. Pero como

4 La importancia de las traducciones ha sido generalmente ignorada en las dinámicas interculturales. Sobre el tema, ver el texto Las Hojas Sabias de Sarrazin.

5 Esto es aún más curioso si se considera que aquellos occidentales que apoyan este "líder espiritual” son quienes más están a favor de una separación entre la política estatal y la religión. 
afirma López, esas representaciones románticas no corresponden con las realidades de una sociedad con una aristocracia apegada a sus privilegios, monasterios que bloquean reformas para conservar el poder, complots e intrigas políticas.

$\mathrm{Si}$ bien parece generoso con Oriente el imaginarlo espiritual y contemplativo en oposición a un Occidente materialista y guerrero, es una simplificación extrema basada en una dicotomía esencialista de origen colonial. Esta dicotomía ignora que "las sabidurías griegas [...] se fundaron sobre preocupaciones muy cercanas a las que hoy se atribuyen a la espiritualidad oriental" (Weinberg 28), y que, inversamente, el pensamiento de las sociedades orientales nunca ha olvidado sus intereses materiales ni ha sido ajeno al racionalismo (Goody). Por todas estas razones se evidencia la necesidad de analizar algunos de los factores culturales que han contribuido a desarrollar estas concepciones.

\section{Nuevas Formas del Creer}

Los años 60's muestran una nueva oleada de interés por las religiosidades orientales en el marco de movimientos como el de contracultura y el hipismo que caracterizan la época. Sin embargo, este fenómeno se distingue de lo ocurrido en el siglo XIX por su carácter mucho más difundido, favorecido por el desarrollo de las tecnologías de transporte y comunicación. En aquellos movimientos es evidente una búsqueda de nuevas experiencias, sensaciones, modelos de vida o formas de pensamiento, lo cual contribuye a difundir un pluralismo que valoriza las "otras culturas" y las alternativas culturales que ellas representarían, tema al que nos referiremos más adelante. Como ya se dijo, Oriente tuvo acá un lugar preponderante.

Posteriormente, en los años 80's, surgieron las tendencias de tipo New $\mathrm{Age}^{6}$, donde se destaca de nuevo el discurso sobre la necesidad de

6 Este tipo de prácticas y creencias no se circunscribe a una organización o movimiento institucionalizado. Sobre el tema existe una amplia literatura, de la cual Wood (1-39) hace una importante revisión crítica, y Sarrazin en "New Age" plantea su vigencia en el contexto latinoamericano. 
un cambio con respecto al materialismo de la modernidad occidental, pero se insiste más aun en la necesidad de desarrollar la espiritualidad individual y cuidar la salud del cuerpo, la mente y el espíritu. Para alcanzar todo lo anterior, se remite a distintas fuentes, entre las cuales se destacan nombres asociados a Oriente como el yoga, la meditación y el budismo, o el reiki y el tai-chi. Religiones, filosofías o terapias orientales son bienvenidas para "enriquecernos espiritualmente" y ayudarnos a alcanzar el bienestar "integral".

Todo este movimiento orientalista se inscribe en nuevas formas del creer individualizado, desinstitucionalizado, descentralizado y desregulado (Beck). Los individuos, emancipados del monopolio institucional de una sola religión, escogen maestros o guías, doctrinas y tradiciones, y practican "sin compromiso" según sus criterios personales. Así, las religiones históricas como el budismo han sido transformadas en "una reserva de signos y de valores que no se inscriben en pertenencias precisas y comportamientos regulados por las instituciones religiosas" (Hervieu-Léger 259). Se trata entonces de un extraño préstamo que hace la modernidad a la tradición.

La dialéctica de la ruptura entre estos dos términos, antes vistos como antagónicos y mutuamente excluyentes, cede progresivamente a una dinámica de la amalgama (Baudrillard 113-129). Queremos conservar nuestros dispositivos tecnológicos con conexión a internet, pero también pretendemos conectarnos con la herencia de una religión tradicional y de origen lejano. En realidad se trata de una amalgama consumista con criterio pragmático: "si funciona, ¿̇por qué rechazarlo?".

De manera similar, apropiarse de una identidad religiosa no parece tener mucha importancia para estas personas, quienes no riñen con la idea de ser a la vez budistas $y$ cristianos (Lenoir, Le Bouddhisme 291)7. De hecho, el budismo es definido por muchos occidentales no como una

7 Si bien estas personas han rechazado la imposición autoritaria de una institucionalidad religiosa como el catolicismo de sus padres, ello no significa, evidentemente, que los esquemas culturales cristianos, con sus símbolos y valores, con su visión del mundo en general, hayan dejado de influir de manera profunda en los individuos. 
religión, sino como una filosofía, una manera de ver el mundo, una actitud de vida, un camino espiritual, un arte de vida cuyo objetivo -muy moderno- es la transformación interior y el bienestar personal (Liogier, "La Religion" 135). No obstante, se trata de una aproximación a la religión que no implica un cambio verdaderamente radical en el habitus ni en la socialización de las personas.

La constitución social de la religión, o el hecho de que toda religión está necesariamente ligada a una forma de vida social en particular -relaciones interpersonales, estructuras políticas, prácticas económicas, etc.-, no es algo que sea considerado por estos creyentes ultramodernos. Se trata de una visión de la religión y de lo cultural como un conjunto de conocimientos o saberes abstractos que pueden ser separados de las condiciones sociales y los universos simbólicos (Berger) de donde surgen, para ser transpuestos en cualquier otro contexto sociocultural sin problema alguno.

En el mismo sentido, los compromisos con una comunidad religiosa -si es que esta existe- ya no se perciben como obligatorios y se hacen moldeables según los intereses y los ritmos propios del individuo. Así, en los pocos casos en que se concibe una cierta pertenencia a una comunidad budista -o de otra denominación-, no se vive en ella, sino que se participa esporádicamente a ciertos encuentros cuya utilidad y correspondencia con la racionalidad del individuo deben ser evidentes.

Como Droit lo ha señalado, entre la población occidental se percibe un "tanteo espiritual", un interés descomprometido por diferentes "sabidurías". Los sujetos describen itinerarios de búsqueda espiritual donde se observa el paso de una referencia a otra, en una variedad de filosofías, de terapias alternativas, de técnicas y literatura clasificada en las librerías bajo etiquetas como "espiritualidades" o "autoayuda". Esto es la manifestación de un cambio hacia valores propios de las clases medias y altas liberales: por encima de la acumulación de grandes bienes materiales, se valora la movilidad, el bienestar individual, la sensibilidad ambiental, la apertura a la diferencia y la creatividad personal (Liogier, La Religion 138); valores que, no por azar, corresponden con los reproducidos por el 
Dalai-Lama y diferentes monjes budistas célebres y bien posicionados en el mundo occidental.

El buscador espiritual lleva a cabo un cierto "bricolaje" ${ }^{8}$, es decir, ensambla según sus habilidades y objetivos una serie de elementos abstraídos de sus contextos originales de aparición, para combinarlos con otros de maneras no tradicionales. Se trata entonces de utilizar fragmentos de creencias tomados de las religiones históricas, configurándolos según los intereses personales. Este proceder puede ser conceptualizado como una forma de consumo en un mercado que ofrece diferentes bienes simbólicos (Berger y Luckmann), por lo que el buscador es también entendido como un consumidor de elementos religiosos de diversos orígenes.

Es pues en este marco que el sujeto moderno se dirige al budismo, tomando algunos de sus elementos y dándoles nuevos usos y significados. Este proceder como consumidor permite entender que el individuo no prefiera pertenecer exclusivamente a una religión por el resto de su vida. La pertenencia es vista como una atadura innecesaria que podría limitar su búsqueda -y consumo- espiritual permanente. Se cree sin pertenecer a una comunidad de manera unívoca y cerrada (Davie); las personas más bien hacen parte de redes situacionales (Lipovetsky) donde se interrelacionan formando vínculos temporales y/o distantes.

"Cada cual debe encontrar su camino" es una frase típica del medio social al que nos referimos. La corta frase condensa varios factores claves: las palabras "cada cual..." revelan la individuación propia de este creer contemporáneo (Beck); las palabras “...debe encontrar..." demuestran que existe acá una moralidad -implícita-, una deontología que hace que el sujeto "libre" esté, como señala Bauman (2002), obligado a buscar, a elegir, y a hacerlo bien; "...su camino" significa que una espiritualidad alternativa se percibe como un medio para llegar a un fin, el cual, ya lo sabemos, es la realización personal, el bienestar, la felicidad individual; y

8 El concepto de "bricolaje" es ampliamente utilizado para describir estas nuevas formas del creer (ver por ejemplo Hervieu-Léger), pero su uso difundido en los análisis de los sistemas culturales se lo debemos primariamente a Claude Lévi-Strauss. 
cabe añadir que “...su camino” también deja ver que existe una pluralidad de caminos, es decir que tenemos a nuestra disposición una diversidad cultural que cada individuo debe saber aprovechar. El budismo es un camino, pero el chamanismo también lo es. Y hay otros, por supuesto. Los que el mercado de las nuevas formas del creer pueda ofrecer. ¿Cuál de ellos tomar? La respuesta no es tan evidente ni unívoca. A lo largo de su vida, estas personas han escogido diversos "caminos"; transitan uno y luego otro, de la psicología transpersonal pueden pasar al islam y luego al budismo, y en cada uno dicen adquirir experiencias que consideran útiles para alcanzar sus ideales ${ }^{9}$.

En esta dinámica de consumo, también es importante considerar el lado de la "oferta", donde encontramos lamas o chamanes, gurús o pastores; ninguno de ellos tiene asegurada una audiencia, y cualquiera se puede quedar sin seguidores y sin recursos. Ninguno tiene el monopolio del mercado, todos compiten por obtener una posición privilegiada en él. Como las empresas en la sociedad mercantilizada en la que vivimos, cada empresario espiritual capta una parte de los consumidores, y su crecimiento depende de sus capacidades para llenar las expectativas y cumplir con los requerimientos de sentido de un conjunto de personas. Los comportamientos del Dalai-Lama o de los diferentes Rimpochés deben ser analizados dentro de este "mercado religioso" que ahora es globalizado.

\section{La valoración de la Otredad}

Aproximadamente desde los años 90's, con la difusión del New age, se han multiplicado los oferentes de terapias y espiritualidades alternativas. Esto genera una reacción de parte de los consumidores, especialmente los más informados y selectivos, quienes rechazan lo que ellos han considerado como superchería y charlatanería en muchos casos. Ante esta situación, la identidad "realmente oriental" o "étnica" y "tradicional" adquirió aún más valor entre el público que buscaba precisamente

9 Este mismo proceso de cambio de una denominación religiosa a otra se observa, por ejemplo, entre los nuevos convertidos al Islam en Colombia (Sarrazin y Rincón). 
alternativas "auténticas"10. Se imaginaron entonces santuarios que guardan una sabiduría útil para todo ser humano -"patrimonio inmaterial de la humanidad", se dice en otros contextos-. El budismo tibetano, protegido por las altas montañas y monasterios misteriosos, ha tenido un lugar asegurado en este mercado.

Los consumidores buscan la verdadera diferencia respecto a un "Occidente" representado como materialista y destructor, el cual, con su ciencia y sus valores tecnicistas, no proporciona los sentidos trascendentes ni las referencias estables que le permitan al individuo orientarse con seguridad en el mundo (Berger y Luckmann). La modernidad reflexiva (Beck) se mira a sí misma y se juzga insuficiente. Esta situación propulsa la búsqueda de "sabidurías" o "espiritualidades" no occidentales y no modernas, esperando encontrar precisamente alternativas que eviten los problemas generados por el pensamiento moderno.

En este punto cabe hacer un paréntesis comparativo para mencionar el caso de los adeptos al Islam en Occidente. Aunque sean muchas las diferencias entre el Islam y el budismo, los adeptos a una y otra religión justifican su adhesión mediante discursos sorprendentemente similares. En efecto, luego de años de estudiar el fenómeno de los europeos que decidieron en edad adulta convertirse al Islam, Allevi muestra que existe lo que él llama "conversiones intelectuales", realizadas por parte de personas que pertenecen a estratos socioeconómicos medio y alto y con una formación académica superior -mismo sector poblacional al que pertenecen la mayoría de adeptos al budismo-. Estas personas buscan abstraer del mundo musulmán una versión mística, desanclada territorial y socialmente. Es así que "el sufismo, la vía mística del Islam, es la corriente espiritual y de pensamiento que suscita mayor interés por fuera del mundo islámico" (Allevi 139).

Entre los conversos al Islam en Occidente encontramos nuevamente argumentos en contra del modelo occidental moderno, con su

10 Opera acá una forma de anti-sincretismo que, como Stewart y Shaw demuestran, generalmente está motivado por formas de distinción social e intereses de poder. 
secularización y su incapacidad de proveer sentido trascendental para la vida humana (Sarrazin y Rincón). También como en el budismo, el Islam tendría sentido porque no estaría contaminado por el materialismo occidental. Incluso, cuando los sujetos explican por qué escogieron el Islam y no otra religión, sus descripciones se asemejan notablemente a los discursos de los adeptos al budismo: "[...] la búsqueda de una creencia accesible y comprensible, racional, lejos de extraños dogmas como los sacramentos de la trinidad [...] Una religión moderada, de equilibrios" (Allevi 327). Por supuesto, insiste Allevi a lo largo de su estudio que en todo ello hay mucho de una construcción imaginaria de aquella "otra religión".

El interés por una religión no occidental, sea el budismo o el Islam, se debe analizar entonces como el síntoma de una condición de la modernidad. "Oriente se mide siempre en función de Occidente" (Souty 36). En un sector importante de la población con capital cultural relativamente elevado se duda que la "cultura occidental" vaya por buen camino: se cree cada vez menos que la ciencia y la tecnología puedan realmente traer felicidad a la humanidad, se desconfía de la imposición del modelo del Progreso. La valoración del budismo surge entonces en el contexto de un renovado interés por una cierta alteridad.

Al respecto, Droit asegura que: "Oriente se convierte una vez más en un tema de sueños, y en la esperanza de un recurso. Se le considera capaz de satisfacer una demanda difusa, a veces confusa, de una vida diferente" (135). Oriente es como una imagen en negativo de Occidente. Si Occidente se imagina modernista, racional y materialista, Oriente sería lo opuesto: tradicional, sensible y espiritual. Así, en una religión oriental como el budismo, encontraríamos el remedio a nuestros males, remedio que "nuestra cultura" no proporciona.

Paradójicamente, esa búsqueda de alteridad se da al mismo tiempo en que se ignoran las diferencias culturales de las comunidades asiáticas, precisamente porque se insiste en que el budismo auténtico no es necesariamente el de esas gentes, sino el que expresa una espiritualidad universal (Liogier, Le Bouddhisme 21). En efecto, se asume que existen "caminos profundamente similares encontrados en diferentes latitudes, 
todos llevando hacia la interioridad" (Schlegel 2397), una interioridad que evidentemente corresponde con las concepciones de espiritualidad individualizada propias de los occidentales. Esta operación de equivalencias entre las más variadas corrientes "supone descartar o relativizar las formas históricas y concretas de las diversas religiones, para así extraer de ellas solamente algunos aspectos" (Schlegel 2397).

Un ejemplo de ello son los mensajes del Dalai Lama, autor o coautor de más de una centena de libros, premio Nobel de la Paz y "embajador" infatigable del budismo tibetano en todo el mundo, principalmente en el Norte global. Él ha sido uno de los promotores de la idea según la cual todas las religiones tienen un fondo en común. En su libro El Dalai Lama habla de Jesús (Bstan-'dzin-rgya-mtsho [Dalaï-Lama]), el autor pretende señalar los puntos de convergencia entre el budismo y el cristianismo. Allí se encuentran además los comentarios de diferentes personalidades, uno de los cuales resalta "los valores universales de paz, justicia, tolerancia y no violencia" que se observan en las palabras del líder tibetano. De otro lado, el Dalai-Lama convence aún más a su público occidental al asegurar que no es necesario convertirse a su religión -se trata, recordémoslo, simplemente de una sabiduría espiritual útil para todo el que quiera aprender algo de ella. Como todo un pluralista moderno, asegura además que es importante que existan varias religiones, de manera que cada persona pueda recurrir a la que más se adapte a su propio juicio y sensibilidad.

Esas nociones de equivalencia y de sabiduría universal corren paralelas a la suposición de que cada concepto religioso, independientemente de la sociedad que le dio origen, puede ser entendido por cualquier persona en el planeta, igualmente sin tener que considerar su formación y su lengua. Habría algo así como un lenguaje universal de la espiritualidad. Lo más paradójico es que muchas veces las supuestas religiones diferentes son conocidas a través de textos en inglés o a través de traducciones que vienen del inglés. Esa supuesta universalidad de budismo no sólo pretende ignorar, como ya dijimos, las dificultades para comprender los conceptos religiosos por fuera del universo semántico que los soporta, y por fuera del contexto social que les dio origen, sino que también ignora que incluso al interior de una sociedad que habla la misma lengua suelen 
existir diferentes interpretaciones y construcciones de la realidad, así como puntos de vista y moralidades incompatibles entre sí.

Como ejemplos de algunas de las dificultades e incompatibilidades mencionadas, Obadia ha constatado que para la gran mayoría de simpatizantes del budismo en Francia, los temas tradicionalmente budistas representan una parte mínima del léxico de sus discursos. En el mismo sentido, Lenoir (Le Bouddhisme 335) hace notar acertadamente que nociones como la desposesión del yo o el deshacerse de las ilusiones de la individualidad, predicadas por Buda, pasan desapercibidas por los adeptos occidentales, hijos de una modernidad individualista. En cambio, los occidentales alegremente hablan del "karma" como si el concepto se limitara a "la ley de causa y efecto" -lo cual es un concepto perfectamente familiar para cualquier occidental moderno-, y han acogido muy fácilmente el concepto de "reencarnación", asimilándolo a la noción cristiana de resurrección o simplemente a la idea de volver a nacer -lo cual sirve de paliativo a nuestro miedo a la muerte-. Sin embargo, esa interpretación de la "reencarnación" es casi opuesta al objetivo de alcanzar una "iluminación" budista, cuyo fin es precisamente que no haya más reencarnaciones, y no haya más un yo.

\section{Conclusión}

El fenómeno de interés por el budismo en Occidente debe ser entendido como el interés por un budismo adaptado a las nuevas formas del creer que se dan en nuestra modernidad. Son varias las tendencias culturales que han confluido para dar lugar a este budismo occidental que atrae a millones de personas: esoterismo, romanticismo, contracultura, new age. Así, los textos budistas vienen siendo poblados por conceptos que tienen sentido para los occidentales en un recorrido de "aclimatación" que ha durado más de un siglo y se ha efectuado principalmente desde el mundo anglosajón.

Ese recorrido empieza con un hecho fundamental e imprescindible: todo lo que sabemos del budismo es producto de traducciones siempre cuestionables y problemáticas, incluso aquellas que han sido escritas 
por autores nacidos en el Tíbet, como Sogyal Rimpoché. De otro lado, es necesario reconocer que la visibilidad del budismo es un hecho principalmente mediático al cual han contribuido muy minoritariamente individuos tibetanos. Los pocos que han participado en este proceso, frecuente y estratégicamente reproducen los discursos que mejor corresponden con las sensibilidades y expectativas de los occidentales.

Los adeptos al budismo en Occidente se encuentran principalmente en las clases favorecidas y con capital cultural relativamente elevado. Estos sujetos, reivindicando su emancipación de la institucionalidad religiosa propia de sus ancestros, siguen las tendencias generales de individualización en la modernidad y prefieren un budismo desinstitucionalizado y desregulado, del cual toman sólo los elementos que corresponden con sus gustos personales. Así, se desentienden de la mayoría de compromisos y obligaciones que implica la pertenencia a una comunidad religiosa, y evitan las eventuales imposiciones de una autoridad. Este budismo que triunfa en Occidente -a diferencia de lo que ocurre en Asia- no impone deberes colectivos que puedan limitar el valor verdaderamente sagrado para el sujeto moderno: la libertad individual.

Para comprender el éxito del budismo también es necesario considerar que sus adeptos comparten opiniones críticas en contra de "nuestra cultura", y valoran en consecuencia un cambio imaginado en las "otras culturas", reproduciendo así otra tendencia general de la modernidad: el pluralismo. Aunque la división tajante entre una "cultura occidental" y "las otras culturas" es empíricamente insostenible, especialmente en tiempos de globalización, vemos acá el trazado de fronteras imaginarias que permiten idealizar una religión "oriental". Es así como encontramos no simplemente adeptos al budismo, sino buscadores espirituales que anhelan mayor bienestar personal, sentido a su vida o experiencias trascendentes que no esperan ya encontrar en la religión institucional de sus padres ni en lo que ellos denominan la "cultura occidental". El auge del budismo es entonces un ejemplo paradigmático -más no el únicode lo que ocurre con la religiosidad en una modernidad "post-secular" y crítica de sí misma. 
Por demás, la valoración de la alteridad cultural y religiosa corre sobre la suposición -no siempre consciente por parte de los actores- de que existen principios universales que permiten la comprensión de todas las tradiciones del planeta y su aprovechamiento por parte de todos nosotros. Esta supuesta concordancia universal -sin ningún fundamento empíricoimpide ver justamente las diferencias reales y las concepciones del mundo radicalmente diferentes, como aquellas en que una noción de libertad individual como la nuestra no existe. En cambio, conceptos occidentales como espiritualidad, paz, amor, compasión, búsqueda interior o meditación, son proyectados sobre el budismo, haciendo de este un vehículo más para transmitir valores que en realidad hacen parte de la cosmovisión y la moralidad de un sector privilegiado de las sociedades occidentales.

\section{Lista de referencias}

Abric, Jean-Claude. "La recherche du noyau central et de la zone muette des représentations sociales". Méthode d'étude des représentations sociales. Ed. Jean-Claude Abric. Ramonville Saint-Ange: Editions Erès, 2003. 59-80.

Allevi, Stefano. Les convertis à l'Islam : les nouveaux musulmans d'Europe. Paris: LHarmattan, 1999.

Anderson, Benedict. Imagined Communities: reflexions on the origin and spread of nationalism. New York: Verso, 2000.

Baudrillard, Jean. La sociedad de Consumo: sus mitos, sus estructuras. Madrid: Siglo XXI Editores, 2007.

Bauman, Zygmunt. Modernidad líquida. Buenos Aires: Fondo de Cultura Económica, 2002.

Beck, Ulrich. El Dios personal. La individualización de la religión y el "espíritu" del cosmopolitismo. Barcelona: Paidós, 2009.

Berger, Peter. El dosel sagrado: elementos para una sociología de la religión. Buenos Aires: Amorrortu, 1971.

Berger, Peter y Thomas Luckmann. Modernidad, pluralismo y crisis de sentido. Barcelona: Paidós, 1997. 
Bstan-'dzin-rgya-mtsho [Dalai-Lama]. Le Dalaï-Lama parle de Jésus. Paris: Brepols, 1996.

Davie, Grace. "Believing without belonging: Is this the future of religion in Great Britain". Social Compass 37.4 (1990): 455-470.

David-Neel, Alexandra. Mystiques et magiciens du Tibet. Paris: Plon, 1985.

Droit, Roger-Pol. "Chercher des sagesses". Des idées qui viennent. Ed. Roger-Pol Droit y Dan Sperber. Paris: Odile Jacob, 1999.

Evans-Wentz, Walter. The Tibetan Book of the Dead. The after-death experiences on the Bardo plane, according to $L \square$ ma Kazi DawaSamdup's english rendering. London: Oxford University Press, 1927.

Goody, Jack. L'Orient en Occident. Paris: Editions du Seuil, 1999.

Hammer, Olav. Claiming Knowledge: Strategies of Epistemology from Theosophy to the New Age. Leiden, NLD: Brill Academic Publishers, 2004.

Hannegraaf, Wouter "Nouvelle Age". Dictionnaire Critique de l'Esotérisme.

Ed. Jean Servier. Paris: Presses Universitaires de France, 1998. 943-945.

Hervieu-Léger, Danièle. La Religión, Hilo de la Memoria. Barcelona: Herder, 2005.

Hourmant, Louis. "Lattrait du bouddhisme en Occident". Sciences Humaines 106 (2000): 28-31.

Lenoir, Frédéric. Le Bouddhisme en France. Paris: Fayard, 1999.

Lenoir, Frédéric. "Les Spiritualités Orientales en Occident". Encyclopédie des Religions. Vol. II. Ed. Frédéric Lenoir e Ysé Tardan-Masquelier. Paris: Bayard, 2000. 2403-2415.

Lenoir, Frédéric. Las Metamorfosis de Dios: La Nueva Espiritualidad Occidental. Madrid: Alianza Editorial, 2005.

Lévi-Strauss, Claude. El Pensamiento Salvaje. México: Fondo de Cultura Económica, 2009.

$\mathrm{Li}$, Shenwen. Stratégies missionnaires des jésuites français en NouvelleFrance et en Chine au XVIIe siècle. Paris: L'Harmattan, 2001.

Liogier, Raphaël. Le Bouddhisme mondialisé. Paris: Ellipses, 2003. Liogier, Raphaël. "La religion déniée”. Diasporas 3 (2003): 135-147. Lipovetsky, Gilles. La Era del Vacío. Barcelona: Anagrama, 1989. 
López, Donald. Fascination Tibétaine. Paris: Autrement, 2003.

Obadia, Lionel. Bouddhisme et Occident. La diffusion du Bouddhisme Tibétain en France. Paris: L'Harmattan, 1999.

Rampa, Lobsang. Le Troisième OEil. Paris: Editions J'ai lu, 1957.

Said, Edward. Orientalismo. Barcelona: Random House Mondadori, 2004.

Sarrazin, Jean Paul. "New Age en Colombia y la búsqueda de la espiritualidad indígena". Revista Colombiana de Antropología 48.2 (2012): 139-162.

Sarrazin, Jean Paul. Branchés sur la Diversité Culturelle. Enquête sur les représentations et la valorisation du bouddhisme tibétain en Occident. Sarrebruck: Éditions Universitaires Européennes, 2014.

Sarrazin, Jean Paul. "Las Hojas Sabias en Otra Casa. Análisis de la Traducción de la Constitución Política Colombiana a la Lengua Indígena Inga". Signo y Pensamiento 65 (2014.): 16-31.

Sarrazin, Jean Paul y Lina Rincón. "La Conversión al Islam como Estrategia de Cambio y Diferenciación en la Modernidad". Revista de Estudios Sociales 51 (2015): 132-145.

Schlegel, Jean-Louis. "La nouvelle religiosité Occidentale". Encyclopédie des Religions. Vol. II. Ed. Frédéric Lenoir e Ysé Tardan-Masquelier. Paris: Bayard, 2000. 2393-2400.

Sogyal Rinpoché. Le livre de la vie et de la mort. Paris: Table Ronde, 1993.

Souty, Jérôme. "L'Orientalisme, entre science et avatars historiques". Sciences Humaines 118 (2001): 32-37.

Stewart, Charles y Rosalind Shaw. "Introduction: problematizing syncretism". Syncretism/Anti-syncretism. The politics of religious synthesis. Eds. Charles Stewart y Rosalind Shaw. London: Routledge, 1994. 1-25.

Todorov, Tzvetzan. Nosotros y los Otros: reflexión sobre la diversidad humana. México: Siglo XXI, 1991.

Wood, Matthew. Possession, power, and the New Age: ambiguities of authority in neoliberal societies. Aldershot: Ashgate, 2003.

Weinberg, Achille. "Questions sur la pensée orientale". Sciences Humaines 118 (2001): 22-29. 